\title{
Utilization of Energy Storage System based on the Assessment of Area of Severity in Islanded Microgrid
}

\author{
Kyebyung Lee*, Minhan Yoon**, Chang-Hyun Park*** and Gilsoo Jang ${ }^{\dagger}$
}

\begin{abstract}
This paper proposes a method to utilize an energy storage system (ESS) based on the assessment of an area of severity (AOS) to voltage sag. The AOS is defined as a set of the fault positions that can cause voltage sags at many buses simultaneously. The assessment of AOS helps to determine an optimal location of ESS installation to minimize the expected sag frequency (ESF) at concerned buses. The ESS has the ability not only to play traditionally known roles but also to mitigate voltage sag impact on renewable energy sources (RES) in the islanded microgrid. Accordingly, using the proposed method the ESS has additional features to prevent the operation failure of RESs and improve the stability of the microgrid. In order to verify the presented method, a case study was conducted on the sample microgrid system that is modified from an IEEE 57-bus system.
\end{abstract}

Keywords: Voltage sag, Stochastic assessment, Area of severity (AOS), Microgrid, energy storage system (ESS)

\section{Introduction}

Increased power demand requires the expansion of power generation, transmission, and distribution facilities. It can lead to huge losses, a high short circuit capacity and increased operational complexity. Accordingly, the application of small and independent power systems which are electrically separated is being considered more often to solve such problems. The configuration of a system is defined as a microgrid $[1,2]$. In the microgrid, it is important to apply energy storage systems which is able to provide a reference voltage and frequency [3]. In addition, the energy storage system (ESS) is being widely utilized for the purposes of load levelling, power quality enhancement, power levelling of intermittent renewable energy sources (RES), peak shaving, and arbitrage in electricity market, among others.

In an islanded microgrid, inverter-based power sources involving intermittent renewable energy are more dominant than conventional synchronous generator which has high inertia [4]. In this situation voltage sags can cause severe impacts on the grid-connected operation of the power sources. The operation failures of the power sources lead to power shortages and possibly a system blackout. Voltage sag is a sudden voltage decrease phenomenon and mainly caused by faults on transmission/distribution lines. In order to achieve the stable operation of an islanded microgrid, effective countermeasures for reducing voltage sags at

$\dagger$ Corresponding Author: School of Electrical Engineering, Korea University, Seoul, Korea. (gjang@korea.ac.kr)

* School of Electrical Engineering, Korea University, Seoul, Korea. (kyebyung@korea.ac.kr)

** Dept. of Electrical Engineering, Tongmyong University, Busan, Korea. (minhan.yoon@gmail.com)

*** Dept. of Electrical Engineering, Pukyong National University, Busan, Korea. (spch@pknu.ac.kr)

Received: July 9, 2016; Accepted: December 25, 2016 inverter-based power sources are needed. In general, ESS is connected to the microgrid through the voltage source inverter adopting grid-forming control [2]. The ESS has the ability to supply real and reactive power within its rating to maintain a reference voltage and frequency during system disturbances such as voltage sags. Therefore, the power source failures in the microgrid can be reduced by optimally placing and applying the ESS.

Recently, a few studies have focused on the optimal placement of the ESS with RES. [5] proposed a marketbased probabilistic optimal power flow (POPF) with energy storage integration and wind generation to minimize hourly social cost and maximize wind power utilization. [6] proposed a vulnerability assessment and found the optimal locations and capacities of ESSs for power system vulnerability mitigation.

This paper presents a novel utilization of ESS considering optimal placement for increasing system reliability and voltage quality. The optimal placement of ESS is identified based on an area of severity (AOS) and expected sag frequency (ESF) assessment. The AOS is the region of the system where the occurrence of faults will simultaneously lead to voltage sags at the concerned power sources. The ESF is an expected frequency of voltage sags at the power sources. It can be assessed by using the concept of AOS and fault statistics. The ESS model for AOS assessment reflects the probability for the operation state. The proposed method was applied to the modified IEEE-57 test bus system.

\section{Distributed Energy Resources in Microgrid}

\subsection{DERs based on power electronic interface}

The microgrid is defined as a small power system 
isolated from an upper level power system and can be operated in island modes [1-3]. New technical developments in ESS and RES enable the microgrid to autonomously operate and continuously supply electric power to loads without the utility power system. Several microgrids that have different power quality and frequency can be connected with hierarchical structure by a DC system [7]. The microgrid consists of various types of distributed energy resources (DER). Generally, DER systems use RESs such as solar, wind, geothermal, and biomass power. Also, ESS is included in DER. Most RESs are not suitable for direct connection to the electrical network due to the irregular characteristics of the energy they produce. Therefore, power electronic interfaces such as a voltage source inverter (VSI) are required. The control type of the VSI can be classified as grid-forming control or grid-following control according to the characteristics of the energy source [2]. For this reason, the analysis of the power system including DERs is more dependent on characteristics of the VSI control type than characteristics of the input energy source.

The grid-forming VSI regulates output voltages to provide the reference voltage and frequency to the electrical network. In order to maintain the reference voltage and frequency, grid-forming VSI requires rapid responses like stiff DClink voltage of ESS. The ESS with grid-forming VSI can contribute to fault currents within the marginal capacity to maintain the reference voltage and frequency during power system disturbances such as voltage sags. Normally, a droop control method that has the same characteristics as a conventional synchronous machine is adopted. The gridforming VSI based on the droop control method provides the steady-state voltage and frequency as follows $[1,8]$ :

$$
\begin{gathered}
\omega(t)=\omega_{0}-k_{P}\left(P^{*}-P(t)\right) \\
V(t)=V_{0}-k_{Q}\left(Q^{*}-Q(t)\right) \\
k_{P}=\left(\omega_{\min }-\omega_{0}\right) / P_{\max }, \quad k_{P}<0 \\
k_{Q}=\left(V_{\min }-V_{0}\right) / Q_{\max }, \quad k_{Q}<0
\end{gathered}
$$

where $\omega(t)$ is the common operation frequency, $V(t)$ is the terminal voltage of the VSI, $\omega_{0}$ and $V_{0}$ are the rating frequency and voltage of the VSI respectively, $P^{*}$ and $Q^{*}$ are real and reactive power set-points of the VSI, $P(t)$ and $Q(t)$ are real and reactive power outputs of the VSI, and $k_{P}$ and $k_{Q}$ represent the static droop gains.

The grid-following VSI provides the relative voltage and frequency compared to the grid voltage and frequency. Typically, the grid-following VSI adopts decoupled current control including PI controllers as shown in Eq. (5)-(7) [2, 3]. The grid-following VSI limits output currents for protecting VSI during system disturbances. Therefore, it cannot contribute to fault currents.

$$
\mathbf{v}^{*}=v_{d}^{*}+j v_{q}^{*}
$$

$$
\begin{aligned}
& v_{d}{ }^{*}=v_{d}(t)+\left(K_{P i}+\frac{K_{I i}}{s}\right)\left(i_{d}{ }^{*}-i_{d}(t)\right)-\omega(t) L i_{d}(t) \\
& v_{q}{ }^{*}=v_{q}(t)+\left(K_{P i}+\frac{K_{I i}}{s}\right)\left(i_{q}{ }^{*}-i_{q}(t)\right)+\omega(t) L i_{d}(t)
\end{aligned}
$$

where $\mathbf{v}^{*}$ is the vector of output voltage reference of the VSI, $v_{d}{ }^{*}$ and $v_{q}{ }^{*}$ are the reference of $\mathrm{d}$ - and q-axes output voltages of the VSI, $v_{d}(t)$ and $v_{q}(t)$ are the d- and q-axes grid voltages of the VSI, $i_{d}{ }^{*}$ and $i_{q}{ }^{*}$ are the reference of dand q-axes output currents of the VSI, $i_{d}(t)$ and $i_{q}(t)$ are the d- and q-axes output currents of the VSI, $K_{P i}$ and $K_{I i}$ are the proportional and integral gains of PI controller, and $L$ is the interface inductor between the VSI and the electric network.

In the case of DC energy resources such as photovoltaic $(\mathrm{PV})$ power generation or DC generation with a rectifier, a DC to DC converter injects the current into DC-link and increases the DC-link voltage corresponding to the electric power produced. Therefore, the reference of d-axis current is determined to provide electric power by using a DC-link voltage regulator in Eq. (8) for power balance at DC-link.

$$
i_{d}{ }^{*}=-\left(K_{P v d c}+\frac{K_{I v d c}}{s}\right)\left(v_{d c}{ }^{*}-v_{d c}(t)\right)
$$

where $v_{d c}{ }^{*}$ is the reference of DC-link voltage, $v_{d c}(t)$ is the DC-link voltage, and $K_{P v d c}$ and $K_{\text {Ivdc }}$ are the proportional and integral gains of PI controller.

Because of the limit of output current, the grid-following VSI is unable to provide power under voltage sag conditions. When a voltage sag below a certain level occurs, an anti-islanding function can disconnect the grid-following VSI from the grid. According to the IEEE-1547 standard, the grid interconnection of VSI is not allowed under abnormal voltage conditions especially voltage sags below $50 \%$ of nominal. Therefore, grid-following VSI is one of the sensitive equipment to voltage sag. The grid-following VSI is usually applied to fluctuating energy sources such as $\mathrm{PV}$ and wind power.

\subsection{Operation failure of DER in microgrid}

In order for the microgrid to operate in island mode separated from the upper level power system, the reference voltage and frequency must be provided by grid forming VSI $[3,9]$. The ESS with rapid response characteristics is a power source equipment based on grid-forming control. It can provide reference voltage and frequency within its marginal capacity even during power system disturbances. As previously described, however, the operation of power sources based on grid-following control such as intermittent renewable energy sources and HVDC can be failed by power quality problems such as voltage sags. Generally, unpredicted faults in the islanded microgrid can cause severe voltage sags. The voltage sag not only causes operation failure of the major sensitive equipment but also 
leads to disconnection of the grid-following power sources. Because of such a sudden disconnection of power sources, the rest of power sources which have to provide reference voltage and frequency can be overloaded and sequentially shut down. This situation can lead to severe power shortage and blackout. Therefore effective countermeasures for preventing the operation failures of the grid-following power sources during voltage sags are needed. In particular, it is important to reduce the occurrence of severe voltage sags at grid-following power sources, simultaneously.

\section{Voltage Sag Assessment and Area of Severity}

By determining the AOS, the fault region, at which can simultaneously lead to voltage sags below the threshold for normal operation of concerned power sources, can be identified. The AOS is determined from an area of vulnerability (AOV) for each power source. The AOV is the region where the occurrence of faults will lead to voltage sags at a single point $[10,11]$. Therefore, the AOS can be determined by overlapping the AOVs for the concerned source points [12]. Diagrammatically, the AOS is the intersection region of different AOVs. The AOS shows critical region which requires countermeasures for preventing the operation failures of multiple power sources during voltage sags. The methods to determine AOV and AOS have been addressed in [10] and [12], respectively. The AOV and AOS should be separately determined for each fault type and phase, because the characteristics of voltage sags vary according to fault types and phases differently [10]. If there are $n$ concerned points and AOVs, then the AOS has $n$ different levels. The total number of AOS can be expressed as $\sum_{i=1}^{n} C_{i}$.

Fig. 1 shows an example of the AOS for three power source points $\mathrm{A}, \mathrm{B}$ and $\mathrm{C}$. The AOSs are defined as the intersection regions of $\operatorname{AOV}(\mathrm{A}), \operatorname{AOV}(\mathrm{B})$ and $\operatorname{AOV}(\mathrm{C})$.

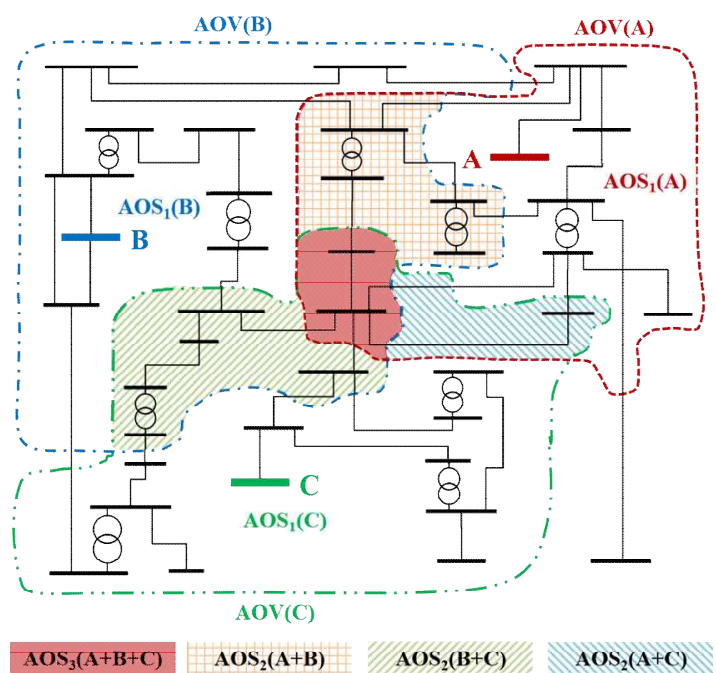

Fig. 1. Concept of AOS for three different source points (A, B, and C)
The $\mathrm{AOS}_{3}(\mathrm{~A}+\mathrm{B}+\mathrm{C})$ (i.e. the AOS of level 3) is the area where the occurrence of faults will simultaneously lead to voltage sags at all three source points. The $\operatorname{AOS}_{2}(\mathrm{~A}+\mathrm{B})$ (i.e. the AOS of level 2) can be determined by excluding $\mathrm{AOS}_{3}$ $(\mathrm{A}+\mathrm{B}+\mathrm{C})$ from the overlapped $\mathrm{AOS}_{1}(\mathrm{~A})$ and $\mathrm{AOS}_{1}(\mathrm{~B})$. The fault occurrences in the $\operatorname{AOS}_{2}(\mathrm{~A}+\mathrm{B})$ will simultaneously lead to voltage sags at the power sources $\mathrm{A}$ and $\mathrm{B}$. In the same way, $\mathrm{AOS}_{1}(\mathrm{~A})$ is determined by excluding $\mathrm{AOS}_{2}$ $(\mathrm{A}+\mathrm{B}), \mathrm{AOS}_{2}(\mathrm{~B}+\mathrm{C}), \mathrm{AOS}_{2}(\mathrm{~A}+\mathrm{C})$, and $\mathrm{AOS}_{3}(\mathrm{~A}+\mathrm{B}+\mathrm{C})$ from $\operatorname{AOV}(A)$. Faults in $\operatorname{AOS}_{1}(A)$ lead to voltage sags at the power source A only.

The ESF at concerned RESs can be estimated by using the concept of AOS and voltage sag assessment. The number of voltage sags to cause operation failures of concerned RESs simultaneously is calculated in terms of multiplying the fault rates of the buses and lines by the number of buses and the total length of the lines inside the AOS. Accordingly, the ESF for severity level $i$ and set $j$ of concerned power sources can be calculated as follows [12]

$$
E S F_{i j}=\sum_{B \in B_{A} O S i j} I_{B} B F R+\sum_{L \in L_{A O S} S_{i j}} I_{L} l_{L} L F R
$$

where $i$ is the severity level, $j$ is the set of concerned power sources in vector $\mathbf{v}_{\mathbf{i}}$ (e.g. $\mathbf{v}_{\mathbf{1}} \in[\mathrm{A}, \mathrm{B}, \ldots, \mathrm{Z}], \mathbf{v}_{\mathbf{2}} \in[\mathrm{AB}$, $\mathrm{BC}, \ldots, \mathrm{YZ}], \mathbf{v}_{\mathbf{3}} \in[\mathrm{ABC}, \mathrm{BCD}, \ldots, \mathrm{XYZ}], \ldots, \mathbf{v}_{\mathbf{n}} \in[\mathrm{ABCD} \ldots$, ...WXYZ]), $A O S_{i j}$ is the AOS according to a severity level $i$ and set $j$ of concerned power sources, $B$ and $L$ are the system bus and line respectively, $B_{A O S i j}$ is the set of all buses inside the $A O S_{i j}, L_{A O S i j}$ is the set of all lines partially or completely inside the $A O S_{i j}, I_{B}$ and $I_{L}$ is conditional sign ( 1 for the bus and line inside the $A O S_{i j}, 0$ for the bus and line completely outside the $\left.A O S_{i j}\right), l_{L}$ is the length of line $L$ inside the $A O S_{i j}$, and $B F R$ and $L F R$ are the bus and line fault rate for each fault type, respectively.

The total ESF for all AOS levels is calculated as

$$
T E S F=\sum_{i=1}^{n} \sum_{j=1}^{m} i \times E S F_{i j}
$$

where TESF is the total ESF, $n$ is the number of concerned power sources, $m$ is the number of combination corresponding to AOS severity level $i$. Also ESF to range in severity from $s$ to $n$ can be calculated using

$$
\mathrm{CESF}_{s-n}=\sum_{i=s}^{n} \sum_{j=1}^{m} i \times E S F_{i j}
$$

where CESF is the cumulative ESF for severity range, and $s$ is the severity level.

\section{ESS Utilization Based on AOS Assessment}

ESS is a power source with energy storage such as a 
flywheel or battery. The most mature and economic stationary battery to be adopted to ESS is a valve regulated lead-acid (VRLA) battery [13]. The ESS with VRLA battery has three operating states: discharge, charge, and end of charge [14]. ESS is operated as a load for the charging state and a generator for the discharging state. In the end of the charge state, a float charge, equalizing charge and idle operation can be included. The battery with high temperature during the charge operation is cooled for the end of charge state. The end of charge state prevents the reduction of battery life by discharging at an elevated temperature [15]. ESS has the scheduling of charge and discharge according to the purpose and usage. In islanded microgrid, the AOS and ESF mainly depend on the location and operating state of the ESS. Thus, the AOS and ESF should be determined for each operating state. Then the final ESF can be estimated by reflecting the probabilities of the operating states. The probabilities can be obtained from average operating time of each state according to the ESS scheduling. Therefore, considering the probabilities of operating states, CESF is calculated by

$$
\operatorname{CESF}_{s-n}\left(P_{k}\right)=\sum_{k=1}^{3} \sum_{i=s}^{n} \sum_{j=1}^{m} P_{k} \times i \times E S F_{i j}
$$

where $k$ is the operating state (1: discharge, 2 :charge, 3 :end of charge), $P_{k}$ is the ESS probability of operation state.

The proposed utilization method involves optimal placement of ESS for minimizing CESF. The minimal CESF means that the simultaneous failures of the gridfollowing power sources by voltage sags can be expected

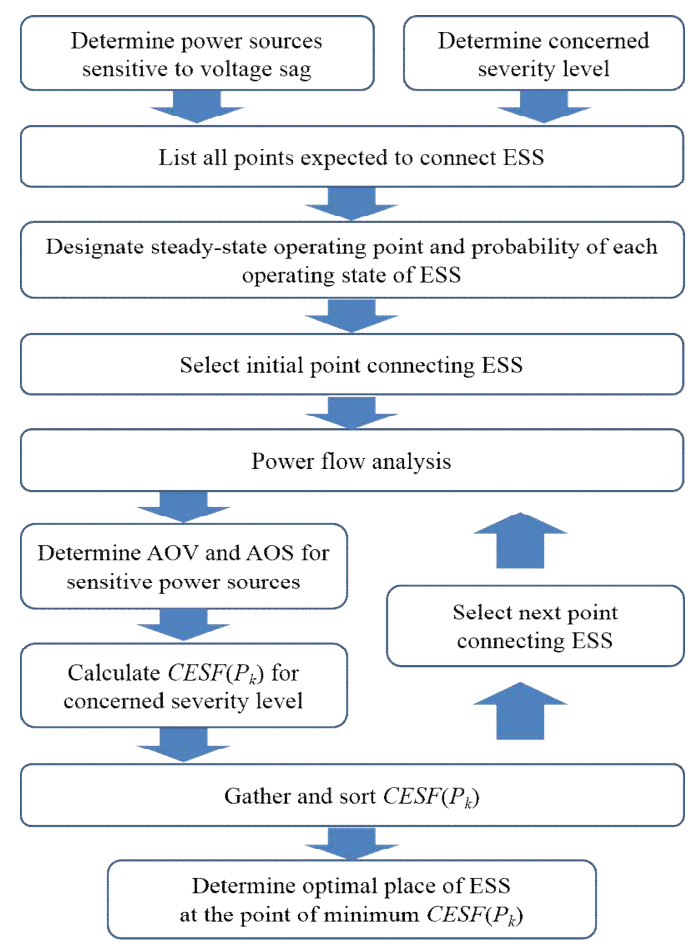

Fig. 2. Procedure for the proposed ESS placement to be minimal. The procedure for determining ESS placement is summarized in Fig. 2.

The power sources sensitive to voltage sags and concerned severity level are determined. The concerned severity level is defined as the AOS level expected to cause unstable system operation or power failure. The steady-state operating point and probability of each operating state of ESS are designated from average operating times and scheduling of ESS. Then, the AOV and AOS for sensitive power sources are determined for each operating state. For all points expected to connect $\operatorname{ESS}, \operatorname{CESF}\left(P_{k}\right)$ is calculated and sorted. Then optimal place of ESS is determined at the point of minimal $\operatorname{CESF}\left(P_{k}\right)$ as

$$
\begin{aligned}
\text { Minimize } & f(N) \\
& =C E S F_{s-n}\left(P_{k}^{N}\right)
\end{aligned}
$$

where $N$ is the number of the bus where ESS is installed.

\section{Case Study}

\subsection{Sample microgrid test system and simulation scenario}

In the case study, the IEEE 57-bus test system was assumed as an islanded microgrid as shown in Fig. 3. The system was modified to properly verify the performance of the proposed scheme. Generators of buses 2, 6 and 9 supplying few reactive power to the system is removed and four RESs were placed at buses 19, 31, 42 and 47. The modified system was considered as an islanded microgrid. It was assumed that if four RESs is failed, the entire system is collapsed.

The total real and reactive power consumed at all loads is 1250.8 [MW], 336.3[MVAr]. The RESs supply only real power through the grid-following VSI with a unity power factor. Average output real power of each RES is $20[\mathrm{MW}]$

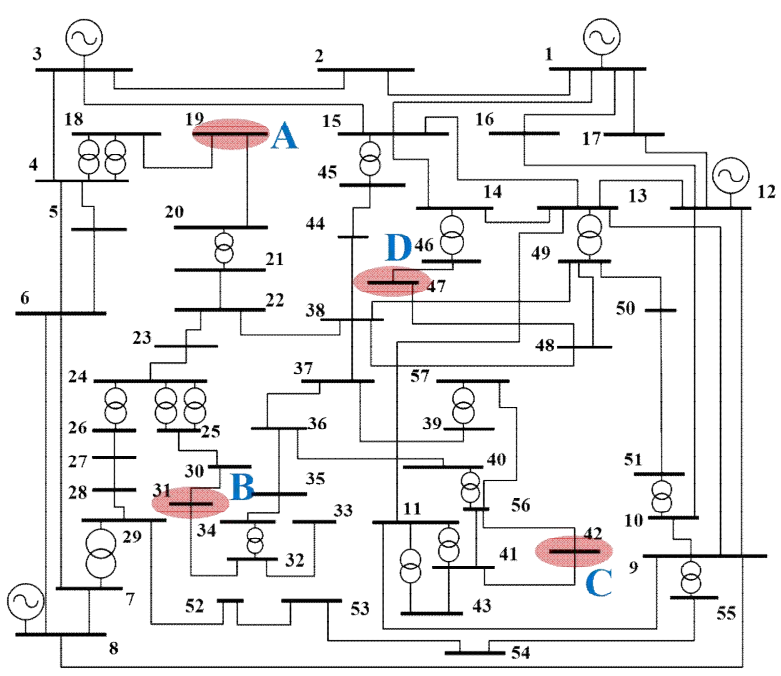

Fig. 3. Modified IEEE 57-bus test system 
respectively and total of the real power is $80[\mathrm{MW}]$. In this study, the voltage threshold of four RESs was assumed to be $55[\%](0.55[$ p.u.]) and the duration of voltage sag was not considered. The rest of the parameters for the IEEE 57bus system is available from [16]. Historical fault rates for the buses and lines are 0.1 (event/year) and 4.2 (event $/ 100 \mathrm{~km} /$ year) respectively [12]. Assuming that the fault-type distribution is to be $80 \%$ (SLGF), $5 \%$ (LLF), $11 \%$ (DLGF) and $4 \%$ (3PF), respectively, the detail fault statics is given Table 1.

Two cases of RES failure due to voltage sags were taken into account in the study. In the first case, ESS placement was determined to prevent simultaneous failures of three among the four RESs. In the second case, the simultaneous failures of all four RESs was considered. Each case assumes the situation when a power shortage problem is occurred by simultaneous failures of RESs in the islanded microgrid. If the microgrid does not respond immediately to the power shortage, the system would become unstable.

\subsection{ESF Assessment}

The AOVs for the RESs were determined for each fault type and phase. Then the AOS is also identified by overlapping the AOVs. Fig. 4 shows the AOS due to $3 \mathrm{PF}$

Table 1. System fault statistics for lines

\begin{tabular}{c|c|c}
\hline Type of Fault & $\begin{array}{c}\text { Bus Fault Rate } \\
\text { (event/year) }\end{array}$ & $\begin{array}{c}\text { Line Fault Rate } \\
\text { (Event/100km/year) }\end{array}$ \\
\hline SLGF & 0.080 & 3.360 \\
\hline LLF & 0.005 & 0.210 \\
\hline DLGF & 0.011 & 0.462 \\
\hline 3PF & 0.004 & 0.168 \\
\hline
\end{tabular}

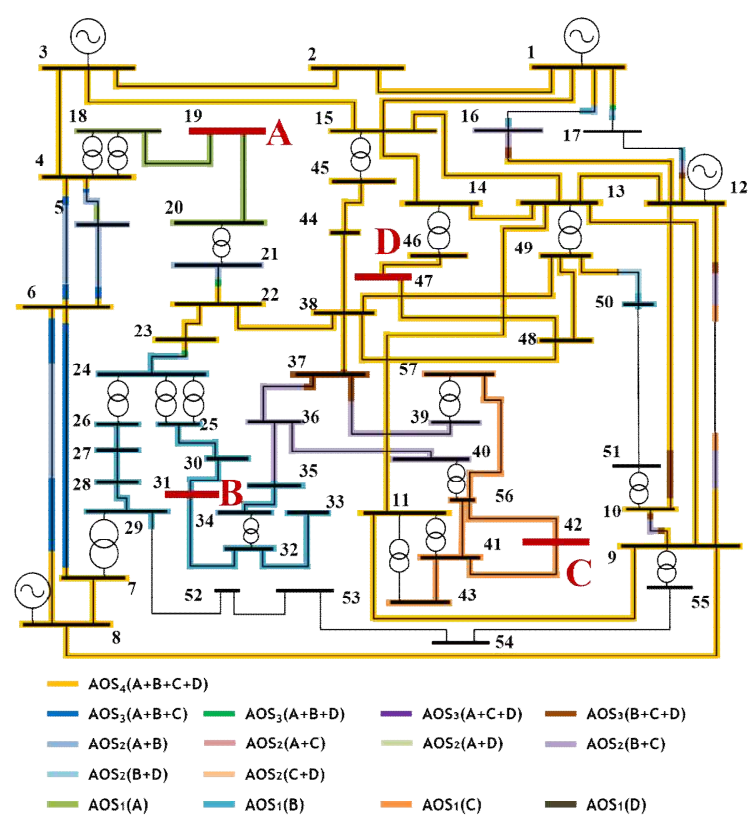

Fig. 4. Area of severity (AOS) due to 3PFs for given test system
Table 2. ESFs (event/year) according to severity levels

\begin{tabular}{|c|c|c|c|c|c|}
\hline \multirow{2}{*}{$\begin{array}{c}\text { Severity } \\
\text { Level }\end{array}$} & $\mathbf{A O S}_{1-4}$ & \multicolumn{2}{|c|}{$\mathrm{AOS}_{3-4}$} & \multicolumn{2}{|r|}{$\mathrm{AOS}_{4}$} \\
\hline & TOTAL & \multicolumn{2}{|c|}{$\left(\mathrm{AOS}_{3}+\mathrm{AOS}_{4}\right)$} & \multicolumn{2}{|c|}{$(\mathrm{A}+\mathrm{B}+\mathrm{C}+\mathrm{D})$} \\
\hline Event/year & 35.70 & & & & 2.950 \\
\hline \multirow{2}{*}{$\begin{array}{c}\text { Severity } \\
\text { Level }\end{array}$} & \multicolumn{5}{|c|}{$\mathbf{A O S}_{3}$} \\
\hline & $(\mathrm{A}+\mathrm{B}+\mathrm{C})$ & $(\mathrm{A}+\mathrm{B}+\mathrm{D})$ & \multicolumn{2}{|c|}{$(\mathrm{A}+\mathrm{C}+\mathrm{D})$} & $(B+C+D)$ \\
\hline Event/year & 0.170 & 0.328 & 0.0 & & 0.220 \\
\hline \multirow{2}{*}{$\begin{array}{c}\text { Severity } \\
\text { Level }\end{array}$} & \multicolumn{5}{|c|}{$\mathrm{AOS}_{2}$} \\
\hline & $(\mathrm{A}+\mathrm{B})$ & $(\mathrm{A}+\mathrm{C})$ & $(\mathrm{A}+$ & & $(B+C)$ \\
\hline Event/year & 0.363 & 0.000 & 0.0 & & 0.516 \\
\hline \multirow{2}{*}{$\begin{array}{c}\text { Severity } \\
\text { Level }\end{array}$} & \multicolumn{2}{|c|}{$\mathrm{AOS}_{2}$} & & & \\
\hline & $(B+D)$ & $(\mathrm{C}+\mathrm{D})$ & & & \\
\hline Event/year & 1.792 & 0.000 & & & \\
\hline \multirow{2}{*}{$\begin{array}{l}\text { Severity } \\
\text { Level }\end{array}$} & \multicolumn{5}{|c|}{$\mathbf{A O S}_{1}$} \\
\hline & (A) & (B) & $(\mathrm{C}$ & & (D) \\
\hline Event/year & 2.863 & 6.077 & 5.0 & & 2.445 \\
\hline
\end{tabular}

Table 3. Parameters of the energy storage system

\begin{tabular}{c|c|c|c}
\hline & Discharge & Charge & End of charge \\
\hline$P^{*}[\mathrm{MW}]$ & 20.0 & -20.0 & 0.0 \\
\hline$Q^{*}[\mathrm{MVAr}]$ & 5.0 & 0.0 & 0.0 \\
\hline Probability & 0.4 & 0.4 & 0.2 \\
\hline
\end{tabular}

for the RESs. The ESFs at the RESs were estimated from the determined AOVs and the fault statistics. The ESFs according to the severity levels of the AOSs are reported in Table 2. Total ESF at four RESs is 35.70 (event/year), and the ESF for $\mathrm{AOS}_{4}(\mathrm{~A}+\mathrm{B}+\mathrm{C}+\mathrm{D})$ which all RESs can simultaneously experience voltage sags below the threshold is 2.95 (event/year). This means that the RESs can be simultaneously shutdown about three times per year. If other power sources do not respond immediately to the sudden lack of power, the system would become unstable and could be faced with a blackout.

\subsection{ESS placement}

When a fault causing voltage sag occurs, the gridforming type of ESS can contribute fault current to the system and support system voltages within its capacity. Hence, the shutdown of RESs caused by voltage sags can be reduced by operating ESS. The probability of an operation state and the steady-state operating point of the ESS are given in Table 3. In order to place the ESS, each of the cases requires a different severity level of AOS. In the first case, the operation failure of three or more RESs must be prevented. Therefore, the ESS site reducing $\operatorname{CESF}_{3-4}\left(P_{k}\right)$ for more $\mathrm{AOS}_{3}$ severity level should be determined. In the second case, the operation failure of all four RESs must be prevented. Therefore, the ESS site reducing $\operatorname{CESF}_{4}\left(P_{k}\right)$ for more $\mathrm{AOS}_{4}$ severity level should be determined.

In this study, 10 buses were selected as the proposed points for installing ESS. Then, CESF was calculated for the points (see Table 4). In the first case that the simultaneous failures of three or more grid-following power sources are concern, $\operatorname{CESF}_{3-4}\left(P_{k}\right)$ for the $\mathrm{AOS}_{3-4}\left(\mathrm{AOS}_{3}+\mathrm{AOS}_{4}\right)$ is 
Table 4. ESFs (event/year) and change level according to concerned severity levels

\begin{tabular}{|c|c|c|c|c|}
\hline \multirow{3}{*}{ ESS Bus } & \multirow{2}{*}{\multicolumn{2}{|c|}{$\begin{array}{c}\mathrm{AOS}_{3-4} \\
\left(\mathrm{AOS}_{3}+\mathrm{AOS}_{4}\right)\end{array}$}} & \multirow{2}{*}{\multicolumn{2}{|c|}{$\frac{\mathrm{AOS}_{4}}{(\mathrm{~A}+\mathrm{B}+\mathrm{C}+\mathrm{D})}$}} \\
\hline & & & & \\
\hline & ESFs & Reduced rate & ESFs & Reduced rate \\
\hline 16 & 3.062 & $16.52 \%$ & 2.309 & $21.73 \%$ \\
\hline 25 & 2.487 & $32.20 \%$ & 0.070 & $97.63 \%$ \\
\hline 26 & 2.169 & $40.87 \%$ & 1.383 & $53.12 \%$ \\
\hline 29 & 2.940 & $19.85 \%$ & 2.158 & $26.85 \%$ \\
\hline 36 & 1.558 & $57.52 \%$ & 0.618 & $79.05 \%$ \\
\hline 38 & 1.592 & $56.60 \%$ & 1.116 & $62.17 \%$ \\
\hline 44 & 1.982 & $45.97 \%$ & 1.489 & $49.53 \%$ \\
\hline 49 & 2.044 & $44.27 \%$ & 1.550 & $47.46 \%$ \\
\hline 55 & 3.022 & $17.61 \%$ & 2.237 & $24.17 \%$ \\
\hline 57 & 2.668 & $27.26 \%$ & 0.416 & $85.90 \%$ \\
\hline \multirow{2}{*}{ ESS Bus } & \multicolumn{4}{|c|}{$\mathrm{AOS}_{3}$} \\
\hline & $(\mathrm{A}+\mathrm{B}+\mathrm{C})$ & $(\mathrm{A}+\mathrm{B}+\mathrm{D})$ & $(\mathrm{A}+\mathrm{C}+\mathrm{D})$ & $(B+C+D)$ \\
\hline 16 & 0.088 & 0.391 & 0.000 & 0.274 \\
\hline 25 & 0.000 & 0.000 & 2.413 & 0.004 \\
\hline 26 & 0.007 & 0.183 & 0.537 & 0.059 \\
\hline 29 & 0.038 & 0.381 & 0.000 & 0.363 \\
\hline 36 & 0.014 & 0.417 & 0.498 & 0.011 \\
\hline 38 & 0.076 & 0.211 & 0.031 & 0.158 \\
\hline 44 & 0.084 & 0.248 & 0.003 & 0.158 \\
\hline 49 & 0.153 & 0.281 & 0.000 & 0.060 \\
\hline 55 & 0.046 & 0.462 & 0.000 & 0.277 \\
\hline 57 & 0.000 & 2.239 & 0.000 & 0.013 \\
\hline
\end{tabular}

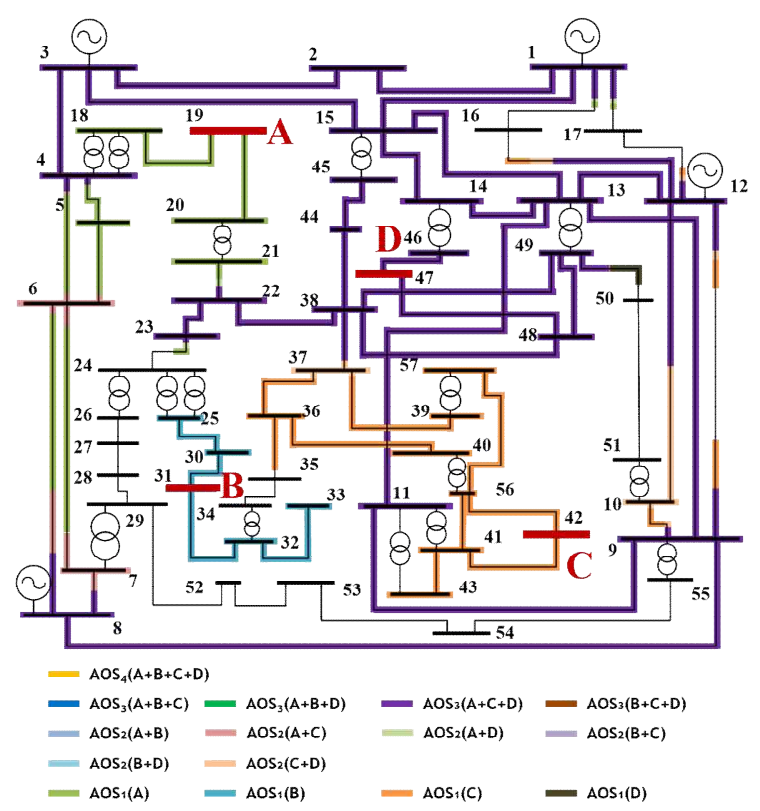

Fig. 5. Area of severity (AOS) due to 3PFs with ESS at bus 25

required. From the results, the point showing the minimal $\operatorname{CESF}_{3-4}\left(P_{k}\right)$ is identified as bus 36. When the ESS was placed at bus 36 , it is observed the $\operatorname{CESF}_{3-4}\left(P_{k}\right)$ was reduced from 3.668(event/year) to 1.558 (event/year) and its reduced rate is $57.52 \%$ comparing before ESS placement. In the second case that the simultaneous failure of four grid-following power sources is concern, $\operatorname{CESF}_{4}\left(P_{k}\right)$ for the $\mathrm{AOS}_{4}$ is required. The point showing the minimal
$\operatorname{CESF}_{4}\left(P_{k}\right)$ is identified as bus 25. When the ESS was placed at bus 25 , the $\operatorname{CESF}_{4}\left(P_{k}\right)$ was reduced from 2.950 (event/year) to 0.070 (event/year) and its reduced rate is $97.63 \%$ comparing before ESS placement. While the ESS operates as generator for discharging state at bus 25, AOS assessment due to the $3 \mathrm{PF}$ for four grid-following power sources and threshold voltage in the test system is shown as Fig. 5. Comparing Fig. 5 with Fig. 4 before ESS is placed, the optimal place of ESS considering the $\operatorname{CESF}\left(P_{k}\right)$ reduces voltage sag for the whole system. Also, the optimal place reduces the simultaneous failure rate of four grid-following power sources by voltage sags.

\section{Conclusion}

This paper presented a novel approach to ESS utilization for preventing operation failures of grid-following type of RESs in an islanded microgrid. Even a single voltage sag can cause shutdown of RESs and lead to blackout. The ESS has the ability to contribute fault current and maintain system voltage. Thus, an ESS with high capacity can ensure stable operation even under disturbance conditions like the voltage sag phenomenon. The proposed method can be used to prevent the simultaneous failure of gridfollowing RESs.

The effective placement of ESS can be determined basically by assessing the AOS and ESF. The fault regions expected to simultaneously lead to voltage sags at RES points can be identified by AOS assessment. In addition, the number of voltage sags at the RESs can be estimated by using the AOS and system fault statistics. The ESS placement is determined as the point at which the least voltage sags are expected to occur at the concerned RESs. The ESS utilization based on the proposed method would help with the mitigation of voltage sags and stable operation of a microgrid involving a large number of RESs without the functions of FRT and LVRT.

\section{Acknowledgements}

This work was supported by "Human Resources program in Energy Technology" of the Korea Institute of Energy Technology Evaluation and Planning(KETEP) granted financial resource from the Ministry of Trade, Industry \& Energy, Republic of Korea(No. 20154030200610, and No. 20131020000100).

\section{References}

[1] R. H. Lasseter and P. Piagi, "Providing Premium Power through Distributed Resources," in Proc. the 33rd Hawaii International Conf. on System Sciences, 
pp. 1437-1445, Jan. 4-7 2000.

[2] F. Katiraei, R. Iravani, N. Hatziargyriou, and A. Dimeas "Microgrids Management," IEEE power \& energy magazine, vol. 6, no. 3, pp. 54-65, May/June 2008.

[3] J. A. Pecas Lopes, C. L. Moreira, and A. G. Madureira, "Defining Control Strategies for MicroGrids Islanded Operation," IEEE Trans. Power Systems, vol. 21, no. 2, pp. 916-924, May 2006.

[4] N. Jayawarna, C. Jones, M. Barnes, and Nick Jenkins, "Operating MicroGrid Energy Storage Control during Network Faults," in Proc. 2007 IEEE International Conference on System of Systems Engineering, pp. 17, Apr. 16-18 2007.

[5] M. Ghofrani, A. Arabali, M. Etezadi-Amoli, and Mohammed Sami Fadali, "A Framework for Optimal Placement of Energy Storage Units within a Power System with High Wind Penetration", IEEE Trans. Sustainable Energy, vol. 4, no. 2, pp. 434-442, April 2013.

[6] J.-H. Teng, C.-Y. Chen, and I. C. Martinez, "Utilising Energy Storage Systems to Mitigate Power System Vulnerability", IET Gener. Transm. Distrib., vol. 7, no. 7, pp. 790-798, 2013.

[7] Johan Driesen and F. Katiraei, "Design for Distributed Energy Resources," IEEE power \& energy magazine, vol. 6, no. 3, pp. 33-39, May/June 2008.

[8] M. C. Chandorkar, D. M. Divan, and R. Adapa, "Control of Parallel Connected Inverters in Standalone ac Supply systems," IEEE Trans. Industry Applications, vol. 29, no. 1, pp. 136-143, Jan./Feb. 1993.

[9] C. L. Moreira, F. O. Resende, and J. A. Pecas Lopes, "Using Low Voltage MicroGrids for Service Restoration," IEEE Trans. Power Systems, vol. 22, no. 1, pp. 395-403, Feb. 2007.

[10] C. H. Park and G. Jang, "Stochastic Estimation of Voltage Sags in a Large Meshed Network," IEEE Trans. Power Del., vol. 22, no. 3, pp. 1655-1664, Jul. 2007.

[11] M. H. J. Bollen, Understanding Power Quality Problems: Voltage Sags and Interruptions, ser. IEEE Power Eng. Ser. Piscataway, NJ: IEEE Press, 2000.

[12] C. H. Park, J. H. Hong, and G. Jang, "Assessment of System Voltage Sag Performance based on the Concept of Area of Severity" IET Gener. Transm. Distrib., vol. 4, no. 6, pp. 683-693, 2010.

[13] X. Tan, Q. Li, H. Wanga, "Advances and Trends of Energy Storage Technology in Microgrid," International Journal of Electrical Power \& Energy Systems, vol. 44, no. 1, pp. 179-191, Jan. 2013.

[14] P. E. Pascoe and A. H. Anbuky, "A VRLA Battery Simulation Model," Energy Conversion and Management, vol. 45, no. 7-8, pp. 1015-1041, May 2004.

[15] Farret Felix A., and Marcelo Godoy Simões, Integration of Alternative Sources of Energy, IEEE
PRESS, 2006.

[16] IEEE 57-Bus Test Case, [Online]. Available: http://www.ee.washington.edu/research/pstca/pf57/pg _tca57bus.htm

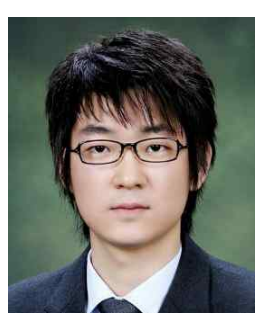

Kyebyung Lee $\mathrm{He}$ received the B.S. and M.S. degrees from Dong-Eui University, Busan, Korea in 2006 and 2008 respectively. $\mathrm{He}$ is currently pursuing Ph.D degree at Korea University graduate school. His research interests include power quality and power system control.

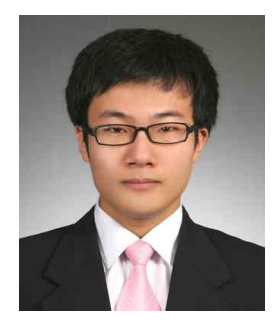

Minhan Yoon He received the B.S. degree and the Ph.D. degree from the Department of Electrical Engineering, Korea University, Seoul, Korea, in 2009 and 2015, respectively. He was a Post-doctoral Research Associate in Seoul National University, Seoul, Korea, in 2015, and a Senior Engineer with Korea Electrotechnology Research Institute (KERI) during 2015-2017. In 2017, he joined the Department of Electrical Engineering, Tongmyong University, Busan, Korea, as an Assistant Professor. His research interests include power system transients and AC-DC system interactions.

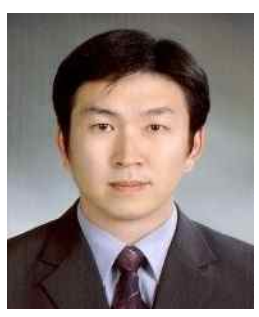

Chang-Hyun Park He received the B.S. degree from Inha University, Incheon, Korea, in 2001, and the Ph.D. degree from Korea University, Seoul, Korea, in 2007. Currently, he is an Associate Professor in the Dept. of Electrical Engineering at Pukyong National University. His research interests include power quality assessment, data visualization, and computer simulation of power systems.

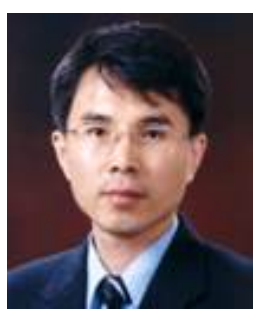

Gilsoo Jang He received the B.S. and M.S. degrees in electrical engineering from Korea University, Seoul, Korea, in 1991 and 1994, respectively, and the $\mathrm{Ph} . \mathrm{D}$. degree in electrical and computer engineering from Iowa State University, Ames, in 1997. He was a Visiting Scientist at Iowa State University from 1997 to 1998 and a Senior Researcher with the Korea Electric Power Research Institute, Daejeon, Korea, from 1998 to 2000. Currently, he is a Professor in the School of Electrical Engineering, Korea University. His research interests include power quality and power system control. 